\title{
28 day post-operative persisted hypercoagulability after surgery for benign diseases: a prospective cohort study
}

\author{
Jan Ulrych', Tomas Kvasnicka ${ }^{2,5^{*}}$, Vladimir Fryba', Martin Komarc ${ }^{3,4}$, Ivana Malikova ${ }^{2}$, Filip Burget ${ }^{1}$,
} Radka Brzezkova ${ }^{2}$, Jan Kvasnicka Jr ${ }^{1}$, Zdenek Krska ${ }^{1}$ and Jan Kvasnicka ${ }^{2}$

\begin{abstract}
Background: Surgery for benign disease is associated with a low-risk of developing venous thromboembolism (VTE). Despite a relatively low incidence of postoperative VTE in patients after elective cholecystectomy and abdominal hernia repair there are data proving hypercoagulability in the early postoperative period. We focused on assessment of the systemic inflammatory response and coagulation status in these surgical patients after hospital discharge.

Methods: Prospectively, patients who underwent surgery for benign disease were included. Two hundred sixteen patients were enrolled - 90 patients in laparoscopic cholecystectomy (LC) group and 126 patients in hernia surgery (HS) group. Risk assessment of VTE according to the Caprini risk assessment model was performed in all patients. Prevalence of VTE in postoperative period was observed. Markers of systemic inflammatory response (IL-6, CRP, a-1-acid glycoprotein, transferrin) and coagulation markers (PLT, fibrinogen, prothrombin fragment F1 +2 and D-dimer) were measured before surgery, on 7-10th postoperative day and on 28-30th postoperative day.
\end{abstract}

Results: Clinically apparent deep vein thrombosis was diagnosed in only one patient - $0.46 \%$. Statistically significant elevation of inflammatory markers IL-6, CRP and a-1-acid glycoprotein ( $p<0.001$; all) were proved in both groups of patients on 7-10th postoperative day. Statistically significant elevation of coagulation markers PLT, fibrinogen, prothrombin fragment F1 +2 and D-dimer $(p<0.001$; all) were proved in LC and HS groups on 7-10th postoperative day. No statistical difference was observed in IL-6, CRP and a-1-acid glycoprotein levels a month after surgery as compared with preoperative levels within each group. Statistically significant elevation of fibrinogen and prothrombin fragment F1 +2 levels ( $p<0.001$; both) persisted on 28-30th postoperative day in both groups. Persisted elevation of D-dimer levels was proved only in HS group $(p<0.001)$, not in LC group $(p=0.138)$, a month after surgery.

Conclusions: Activated systemic inflammatory response and hypercoagulable condition were verified in patients after laparoscopic cholecystectomy and hernia surgery after their hospital discharge. Hypercoagulability persisted even a month after surgery. Nevertheless, we observed very low prevalence of clinically apparent VTE in patients with in-hospital postoperative VTE prophylaxis.

Trial registration: Trials of the Czech Ministry of Health No. RVO-VFN64165 and NT 13251-4.

Keywords: Hernia repair, Laparoscopic cholecystectomy, Acute phase reaction, Hypercoagulability, Venous thromboembolism (VTE)

\footnotetext{
*Correspondence: Tomas.Kvasnicka@vfn.cz

${ }^{2}$ Thrombotic Center, Institute of Medical Biochemistry and Laboratory

Diagnostics, General University Hospital, Charles University, Prague, Czech

Republic

${ }^{5}$ Thrombotic Centre of Institute of Medical Biochemistry and Laboratory

Diagnostics, General University Hospital, Karlovo namesti 32, 12111 Prague,

Prague 2, Czech Republic

Full list of author information is available at the end of the article
} 


\section{Background}

Abdominal hernia repair, cholecystectomy and varicose vein operation have been considered as low-risk surgery for developing venous thromboembolism (VTE). In the literature, the reported incidence of VTE ranges from $0.08 \%-1.2 \%$ in patients undergoing hernia repair, $0.28 \%-0.53 \%$ in patients after elective laparoscopic cholecystectomy and $0.18 \%$ in patients after varicose vein operation [1-4]. The risk of VTE is usually determined according to the Caprini risk assessment model. Routine pharmacologic prophylaxis of VTE in general surgery is recommended only for moderate and high risk patients [5]. In patients with very low and low risk of VTE only, early mobilisation and/or mechanical prophylaxis of VTE (elastic compression stockings) is recommended [5]. There is no recommendation in the 9th ACCP guidelines regarding the duration of VTE prophylaxis in surgery for benign diseases and no definite consensus exists because of the absence of sufficient numbers of valid data. Postoperative prophylaxis in duration of 7-10 days or VTE prophylaxis until full mobilisation of the patient is recommended most frequently in low risk surgery [6]. Some authors demonstrate the feasibility of short postoperative VTE prophylaxis without higher rates of venous thromboembolism. They recommend individualised duration of VTE prophylaxis administration based on stratification of the VTE risk in concrete patients $[7,8]$. Despite relatively low incidences of postoperative VTE in patients after elective cholecystectomy and abdominal hernia repair, there are data proving hypercoagulability in the early postoperative period. Hypercoagulable status in patients after elective laparoscopic and open surgery has been welldocumented in numerous publications [9-11]. However, most of the previous studies have monitored coagulation status and systemic inflammatory response only in the early postoperative period, most often within $72 \mathrm{~h}$ after surgery [9-17]. We focused on assessment of the systemic inflammatory response and coagulation status in patients after open hernia repair and after laparoscopic cholecystectomy one week and one month after surgery, when these patients were already predominantly out-of-hospital. The patients were compared with the grade of thromboembolic risk according to a new adaptation of the Caprini risk assessment model [5].

\section{Methods}

\section{Patients}

The study was performed as a prospective nonrandomized study from January 2011 to April 2012 and the patients undergoing surgery for benign diseases were included. Altogether 232 consecutive patients were enrolled in our study. 16 patients were dropped out because of incomplete laboratory tests. Thus, we assessed 216 patients, of whom 90 patients underwent a laparoscopic cholecystectomy (LC) and 126 patients underwent an elective abdominal hernia surgery (HS). Inclusion criteria: elective laparoscopic surgery for symptomatic gall stone disease or elective open surgery for abdominal hernia. Exclusion criteria: acute cholecystitis, incarcerated hernia, age $<18$ or $>90$ years, malignancy, VTE in previous 6 months. Basic clinical parameters - age, height, weight, body mass index (BMI), blood pressure, pulse were noted in every patient. A new adaptation of the Caprini risk assessment model was used to assess the VTE risk in every patient preoperatively [5]. Each patient was classified into one of four risk groups - very low risk, low risk, moderate risk and high risk. VTE prophylaxis comprised the use of lower extremity bandages and administration of low-molecular-weight heparin (LMWH) subcutaneously. LMWH was administered once a day up to the hospital discharge or full mobilisation of the patient. In the postoperative period, clinical parameters were observed - length of hospital stay, duration of LMWH administration, postoperative complications and clinically apparent VTE in 30 days' postoperative period. Postoperative complications were assessed according to ClavienDindo classification [18]. Clinical assessment of deep vein thrombosis risk was performed according to the Wells score system [19]. Patients with a Wells score of $>2$ warrant ultrasound examination of legs to verify deep vein thrombosis. Genetic examination was carried out in all patients to exclude hereditary thrombophilia - Factor V Leiden mutation (FVL) and factor II - prothrombin 20210G > A mutation. For monitoring of systemic inflammatory response, these markers were used: interleukin 6 (IL-6), C-reactive protein (CRP), $\alpha$-1-acid glycoprotein (Oroso), transferrin (Trf). For monitoring of postoperative hypercoagulability, these markers were used: platelets count (PLT), fibrinogen (Fbg), prothrombin fragment $\mathrm{F} 1+2(\mathrm{~F} 1+2)$ and D-dimer. Markers of systemic inflammatory response and coagulation markers were measured preoperatively, on 7-10th postoperative day and on 28-30th postoperative day. The study was approved by the ethics committee of the 1st Faculty of Medicine of Charles University and General University Hospital in Prague. Each participant gave written informed consent to be included in the study and with the anonymous publication of data.

\section{Laboratory tests}

Venous blood samples were obtained and administered to Vacutainer ${ }^{\mathrm{TM}}$ pneumatic tubes (Becton Dickinson, Meylan Cedex, France). EDTA blood was used for full blood count. Hemogram was determined with Beckman Coulter UniCel ${ }^{\oplus} \mathrm{DxH} 800$ Cellular Analysis System (Beckman Coulter, Miami, Florida, USA). Citrated platelet 
poor plasma was prepared by double centrifugation at $2500 \times \mathrm{g}$ for $15 \mathrm{~min}$ at room temperature and stored in $1.0 \mathrm{~mL}$ aliquots at $-80{ }^{\circ} \mathrm{C}$ until testing fibrinogen, prothrombin fragment F1 + F2 and D-dimer. Coagulation tests were carried out on a Behring coagulation system (BCS) ${ }^{m}$ analyzer (Dade Behring, Marburg, Germany). Determination of F IIa (trombin) inhibition and concentration level of prothrombin fragment $\mathrm{F} 1+2$ were carried out according to the manufacturer's instructions using the MRX Microplate Reader ${ }^{\mathrm{Tm}}$ microphotometer (Dynatech Laboratories, Chantilly, USA). Fibrinogen was determined using the Fibrinogen reagent kit (product supplied By Technoclone, Austria). Prothrombin fragment F1 + 2 was determined using the Enzygnost ${ }^{\circ} \mathrm{F} 1+2$ micro kit (product supplied by Dade Behring, Marburg, Germany). D-dimer was determined using the ELISA D dimer kit (product supplied by Boehring-Mannheim, Germany). Acute phase proteins (CRP, Oroso, Trf) were determined using the Nephelometer BNII (Dade Behring, Marburg, Germany).

\section{Genetic tests}

Genome DNA was extracted from leukocytes in peripheral blood and isolated using the MagNA Pure LC Nucleic Acid Extraction system ${ }^{\mathrm{Tn}}$ with a MagNA Pure DNA Isolation Kit $\mathrm{I}^{\mathrm{mm}}$. DNA was isolated according to the MagNA Pure High-Performance DNA Extraction ${ }^{\mathrm{Tu}}$ protocol (all products supplied by Roche Diagnostics, Mannheim, Germany). Monitored mutations were determined using PCR in a process called FRET (Fluorescence Resonance Energy Transfer). Tests were performed using the LightCycler ${ }^{\circ} 480$ System with LC 480 Genotyping Master kits (all products supplied by Roche Diagnostics, Mannheim, Germany). Specific primers and fluorescently labelled probes were designed in cooperation with TIB MOLBIOL (Berlin, Germany), where they were custom made.

\section{Statistical analysis}

Basic descriptive statistics within two groups of patients (cholecystectomy, hernia repair) were computed for all variables, which were subsequently tested for normality using Kolmogorov-Smirnov and Shapiro-Wilk tests. Changes in the non-normally distributed systemic inflammatory response markers (IL6, CRP, Oroso, Trf) and coagulant markers (Fbg, D-dimer, PLT, F1 + F2) at three different time points (preoperative, 1 week after surgery and 4 weeks after surgery) were assessed separately within each group of patients by the Friedmann test, followed by a series of Wilcoxon signed rank tests with Bonferroni correction as a post-hoc comparison. $P$-values below 0.05 were considered to be statistically significant. Statistical analysis was performed using SPSS version 22 (SPSS Inc., Chicago, IL, USA).

\section{Results}

\section{Basic characteristics of our study group}

Basic characteristics of our study group are depicted in Table 1. Only patients with uncomplicated symptomatic gallstone disease were included in LC group. All cholecystectomies were finished laparoscopically. The hernia surgery group comprises patients with different types of abdominal hernias - inguinal hernia $n=65$ (51.59\%), incisional hernia $n=26$ (20.63\%), umbilical hernia $n=17$ (13.49\%), epigastric hernia $n=17$ (13.49\%), femoral hernia $n=1(0.79 \%)$. Hernia repair was performed either as a conventional open hernioplasty $\mathrm{n}=95(75.40 \%)$ or open hernia repair with mesh $n=31$ (24.60\%). Risk assessment of VTE in the study population, as per the Caprini risk assessment model, is shown in Table 2.

\section{Postoperative course}

The median length of postoperative hospital stay for both groups was 3 days. Equally, the median length of LMWH administration for patients was 3 days after both types of surgery. Postoperative complications occurred in 6 patients $(2.78 \%)$ - wound hematoma $n=4(1.85 \%)$, postoperative bronchopneumonia $n=1(0.46 \%)$, clinically apparent deep vein thrombosis $n=1(0.46 \%)$. Classification of postoperative complications is shown in Table 3.

\section{Hereditary trombophilia}

Hereditary thrombophilia was detected in 18 patients $(8.33 \%)$ - FVL mutation (heterozygote) in 11 patients (5.12 \%), Factor II 20210G > A mutation (heterozygote) in 6 patients $(2.80 \%)$ and, in one patient, both mutations (FVL and F II 20210G > A heterozygote) were proved. The hereditary thrombophilic status was diagnosed in 8 patients $(8.89 \%)$ in LC group and in 10 patients (7.94\%) in HS group.

\section{Acute phase proteins and coagulation markers Hernia surgery group}

On postoperative day $7-10$, statistically significant elevation of most acute phase proteins were proved as

Table 1 Basic characteristics of study population

\begin{tabular}{lll}
\hline & $\begin{array}{l}\text { Cholecystectomy } \\
\text { Median (IQR) }\end{array}$ & $\begin{array}{l}\text { Hernia surgery } \\
\text { Median (IQR) }\end{array}$ \\
\hline Age (years) & $53.00(38.00-61.25)$ & $58.00(41.50-66.00)$ \\
Height $(\mathrm{cm})$ & $168.50(164.75-176.50)$ & $175.00(170.00-180.00)$ \\
Weight $(\mathrm{kg})$ & $75.00(63.00-85.00)$ & $84.00(74.00-92.50)$ \\
BMl $\left(\mathrm{kg} / \mathrm{m}^{2}\right)$ & $26.15(22.75-28.45)$ & $27.00(24.75-29.90)$ \\
BP syst. $(\mathrm{mmHg})$ & $120.00(120.00-130.00)$ & $120.00(120.00-135.00)$ \\
BP diast. (mmHg) & $80.00(78.75-80.00)$ & $80.00(75.00-80.00)$ \\
Puls (/min.) & $75.00(69.50-76.00)$ & $76.00(70.00-76.00)$ \\
\hline
\end{tabular}

Notes: IQR interquartile range; $B M I$ body mass index; $B P$ blood pressure 
Table 2 Classification of VTE risk in study population according to the Caprini risk assessment model

\begin{tabular}{lll}
\hline Patient stratification & $\begin{array}{l}\text { Cholecystectomy } \\
\text { no. of pts. (\%) }\end{array}$ & $\begin{array}{l}\text { Hernia surgery } \\
\text { no. of pts. (\%) }\end{array}$ \\
\hline Very low risk (0 point) & 0 & 0 \\
Low risk (1-2 points) & $8(8.9 \%)$ & $17(13.5 \%)$ \\
Moderate risk (3-4 points) & $39(43.3 \%)$ & $60(47.6 \%)$ \\
High risk (>5 points) & $43(47.8 \%)$ & $49(38.9 \%)$ \\
\hline
\end{tabular}

compared to preoperative levels - IL-6 $(p<0.001)$, CRP $(p<0.001)$ and $\alpha-1$-acid glycoprotein $(p<0.001)$. Transferrin levels did not differ significantly $(\mathrm{p}=0.074)$. On day 28-30 after surgery, no significant difference in levels of IL-6 $(p=0.281)$, CRP $(p=0.267)$ and $\alpha$-1-acid glycoprotein $(p=0.527)$ were observed as compared with preoperative levels; however, transferrin significantly decreased compared to the preoperative levels $(p=0.001)$. A statistically significant increase in coagulation marker levels was proved on day 7-10 after surgery - PLT, fibrinogen, prothrombin fragment $\mathrm{F} 1+2$ and D-dimer $(p<0.001$; all). On postoperative day 28 30 , only PLT levels did not differ significantly compared to preoperative PLT levels $(p=0.088)$. Persisted elevation of fibrinogen, prothrombin fragment $\mathrm{F} 1+2$ and Ddimer levels $(p<0.001$, all $)$ were observed even one month after hernia surgery (Table 4 ).

\section{Laparoscopic cholecystectomy group}

On postoperative day $7-10$, statistically significant elevation of acute phase proteins were proved as compared to preoperative levels - IL-6 $(p=0.002)$, CRP $(p<0.001)$ and $\alpha-1$-acid glycoprotein $(p<0.001)$. Transferrin levels did not differ significantly $(\mathrm{p}=0.057)$. On day $28-30$ after surgery, no significant difference in levels of IL-6 $(p=0.865)$, CRP $(p=0.074)$ and $\alpha-1$-acid glycoprotein $(p=0.201)$ were observed as compared with preoperative levels; however, transferrin significantly decreased compared to the preoperative levels $(p=0.007)$. A statistically significant increase in coagulation marker levels was proved on day 7-10 after surgery - PLT, fibrinogen, prothrombin fragment $\mathrm{F} 1+2$ and $\mathrm{D}$-dimer $(p<0.001$; all). On postoperative day $28-30$, PLT levels $(p=0.042)$ and $\mathrm{D}$-dimer levels $(p=0.138)$ did not differ significantly compared to preoperative levels. However, persisted elevation of fibrinogen, prothrombin fragment $\mathrm{F} 1+2$ levels $(p=0.002$; both) were observed even one month after laparoscopic cholecystectomy (Table 4).

\section{Discussion}

Given the absence of data related to the duration of postoperative systemic inflammatory response and postoperative hypercoagulability in patients after surgery for benign disease, we focused on the monitoring of inflammatory markers and coagulation markers in patients after open hernia surgery (HS) and after laparoscopic cholecystectomy (LC). Basic characteristics of the study population were assessed separately for more detailed information, not for comparison. Most patients in the HS group and LC group were classified as moderate risk (47.6\% and $43.3 \%$, respectively) and high risk (38.9\% and $47.8 \%$, respectively) according to the new adaptation of the Caprini risk assessment model. The postoperative risk of VTE can also be increased by hereditary thrombophilia and postoperative complications. FVL and Factor II 20210G > A belong among the most frequent hereditary thrombophilia predispositions with a moderate risk of VTE. The frequency of these two hereditary thrombophilic conditions in our study population corresponds to their prevalence in the Czech population [20]. Postoperative complications are an important factor which can affect postoperative systemic inflammatory response and prolong postoperative hypercoagulability. The postoperative complications were acceptably low in our study group. Just et al. reported a complication rate of $2.7 \%$ after hernia surgery and Ahmad et al. reported a complication rate of $5.4 \%$ after laparoscopic cholecystectomy [21, 22]. The median length of LMWH administration is identical to the median length of hospital stay (3 days). This fact corresponds with the generally performed clinical practice of administering pharmacologic VTE prophylaxis only in hospital. There is no definite recommendation concerning the length of administration of pharmacologic VTE

Table 3 Postoperative course and postoperative complications

\begin{tabular}{lll}
\hline & Cholecystectomy & Hernia surgery \\
\hline $\begin{array}{l}\text { Postoperative complications according to } \\
\text { Clavien-Dindo classification (No. of pts.) }\end{array}$ & & Wound hematoma $(n=2)$ DVT $(n=1)$ \\
$\begin{array}{l}\text { Clavien-Dindo II } \\
\text { Clavien-Dindo IIla }\end{array}$ & Postoperative pneumonia $(n=1)$ & Wound hematoma $(n=1)$ \\
Clavien-Dindo IIlb & & Wound hematoma $(n=1)$ \\
Length of hospital stay, days median (range) & $3(2-9)$ & $3(1-10)$ \\
Length of LMWH administration, days median (range) & $3(1-9)$ & $3(1-10)$
\end{tabular}

Notes: DVT deep vein thrombosis; $L M W H$ low molecular weight heparin 
Table 4 Results of monitoring markers

\begin{tabular}{|c|c|c|c|c|c|}
\hline & & \multicolumn{2}{|l|}{ Cholecystectomy } & \multicolumn{2}{|l|}{ Hernia surgery } \\
\hline & & Median (IQR) & $p$-value & Median (IQR) & $p$-value \\
\hline \multirow[t]{3}{*}{ Fbg $(g / l)$} & $\mathrm{Fbg}^{*}$ & $3.56(3.17-3.90)$ & & $3.45(3.05-3.95)$ & \\
\hline & $\mathrm{Fbg}^{\dagger}$ & $4.16(3.66-4.66)$ & $\mathrm{p}_{*+}<0.001$ & $4.37(3.71-5.09)$ & $p_{*+}<0.001$ \\
\hline & $\mathrm{Fbg}^{\ddagger}$ & $3.63(3.25-4.01)$ & $p_{* \neq}=0.002$ & $3.58(3.20-4.22)$ & $p_{* \neq}<0.001$ \\
\hline \multirow[t]{3}{*}{ D-dimer ( $\mu \mathrm{g} / \mathrm{l})$} & D-dimer ${ }^{*}$ & 96.50 (57.00-139.25) & & $104.00(62.00-161.00)$ & \\
\hline & D-dimer ${ }^{\dagger}$ & $409.00(273.50-577.00)$ & $\mathrm{p}_{*_{+}}<0.001$ & $318.50(173.75-554.25)$ & $\mathrm{p}_{*+}<0.001$ \\
\hline & D-dimer $^{\neq}$ & $109.50(67.00-155.50)$ & $p_{* \neq}=0.138$ & $123.00(71.50-216.00)$ & $p_{* \neq}<0.001$ \\
\hline \multirow[t]{3}{*}{$\operatorname{PLT}\left(10^{9} / \mathrm{l}\right)$} & $\mathrm{PLT}^{*}$ & $230.00(200.50-259.50)$ & & $212.00(181.50-248.00)$ & \\
\hline & $\mathrm{PLT}^{\dagger}$ & $267.00(234.50-303.50)$ & $\mathrm{p}_{*+}<0.001$ & $262.00(225.00-312.00)$ & $\mathrm{p}_{*_{+}}<0.001$ \\
\hline & $\mathrm{PLT}^{\ddagger}$ & $227.00(206.00-275.00)$ & $p_{* \neq}=0.042$ & $216.00(183.25-267.00)$ & $p_{* \neq}=0.088$ \\
\hline \multirow[t]{3}{*}{$\mathrm{F} 1+\mathrm{F} 2(\mathrm{nmol} / \mathrm{l})$} & $\mathrm{F} 1+2^{*}$ & $0.17(0.14-0.21)$ & & $0.18(0.14-0.24)$ & \\
\hline & $\mathrm{F} 1+2^{+}$ & $0.24(0.19-0.30)$ & $p_{*+}<0.001$ & $0.26(0.19-0.30)$ & $\mathrm{p}^{*_{+}}<0.001$ \\
\hline & $\mathrm{F} 1+2^{\ddagger}$ & $0.21(0.18-0.25)$ & $p_{* \neq}=0.002$ & $0.23(0.19-0.31)$ & $p_{* \neq}<0.001$ \\
\hline \multirow[t]{3}{*}{$\operatorname{Trf}(g / l)$} & $\operatorname{Trf}^{*}$ & $2.33(2.08-2.65)$ & & $2.29(2.00-2.55)$ & \\
\hline & $\operatorname{Trf}^{\dagger}$ & $2.42(2.28-2.72)$ & $p_{*+}=0.057$ & $2.36(2.10-2.74)$ & $p_{*+}=0.074$ \\
\hline & $\operatorname{Trf}^{\ddagger}$ & $2.09(1.89-2.42)$ & $p_{* \neq}=0.007$ & $2.09(1.96-2.35)$ & $p_{* \neq}=0.001$ \\
\hline \multirow[t]{3}{*}{ Orso (g/l) } & Oroso $^{*}$ & $0.71(0.62-0.81)$ & & $0.73(0.60-0.88)$ & \\
\hline & Oroso $^{+}$ & $0.95(0.82-1.07)$ & $p_{*+}<0.001$ & $1.07(0.85-1.18)$ & $p_{*+}<0.001$ \\
\hline & Oroso $^{\ddagger}$ & $0.69(0.63-0.85)$ & $p_{* \neq}=0.201$ & $0.73(0.57-0.86)$ & $p_{* \neq}=0.527$ \\
\hline \multirow[t]{3}{*}{ CRP (mg/l) } & $\mathrm{CRP}^{*}$ & $0.90(0.45-2.10)$ & & $1.10(0.44-2.60)$ & \\
\hline & $\mathrm{CRP}^{\dagger}$ & $3.47(1.90-5.49)$ & $\mathrm{p}_{*_{+}}<0.001$ & $3.85(1.50-8.13)$ & $\mathrm{p}_{*_{+}}<0.001$ \\
\hline & $\mathrm{CRP}^{\ddagger}$ & $0.66(0.33-1.57)$ & $p_{* \neq}=0.074$ & $1.03(0.57-2.01)$ & $p_{* \neq}=0.267$ \\
\hline \multirow[t]{3}{*}{ IL6 (pg/ml) } & $1 \mathrm{~L} 6^{*}$ & $1.35(0.98-2.06)$ & & $1.61(1.17-2.91)$ & \\
\hline & $\mathrm{IL}^{\dagger}$ & $2.48(1.71-3.12)$ & $\mathrm{p}_{*+}=0.002$ & $3.30(1.97-5.40)$ & $p_{*+}<0.001$ \\
\hline & $\mathrm{IL}^{\ddagger}$ & $1.44(0.97-1.93)$ & $p_{* \neq}=0.865$ & $2.14(1.23-2.82)$ & $p_{* \neq}=0.281$ \\
\hline
\end{tabular}

Notes: IQR - interquartile range; $p$-values - differences tested by Wilcoxon test; ${ }^{*}$ before surgery; ${ }^{\dagger} 7-10$ days after surgery; ${ }^{\ddagger} 28-30$ days after surgery; $p_{*+}-p$-value of the difference between measurement before surgery and 7-10 days after surgery; $p_{*}-p$-value of the difference between measurement before surgery and 28-30 days after surgery

prophylaxis in patients operated on for benign diseases. Tincani et al. published a study in which they observed the prevalence of postoperative VTE in patients undergoing laparoscopic surgery for a benign disease and compared the two different pharmacologic thromboprophylaxis regimens; a short-term pharmacologic thromboprophylaxis (3-4 days in hospital) or an extended-duration pharmacologic thromboprophylaxis (in hospital +7 days after discharge). The prevalence of deep vein thrombosis in patients with the short-term VTE prophylaxis was $0.95 \%$ and the authors concluded that the extended-duration VTE prophylaxis did not provide any benefit [7]. Our results (prevalence of postoperative VTE in our study population - $0.46 \%$ ) support the conclusion that in patients undergoing an uncomplicated surgery for a benign disease, the risk of clinically apparent VTE after hospital discharge is very low (in the case of correct VTE prophylaxis in hospital).
Surgery is associated with the development of a stress reaction by the organism which is called systemic inflammatory response or acute phase reaction. Systemic inflammatory response is a common reaction of the organism to any trauma. Nevertheless, the course and the intensity of the systemic inflammatory response can be influenced by many other factors. Age, obesity, comorbidities and smoking are preoperative factors stimulating the systemic inflammatory response [23]. Systemic inflammatory response markers can be influenced by postoperative complications yet, on the contrary, no impact of the anaesthesia type on the postoperative CRP levels was proved [24, 25]. Cortisol, IL-6, white blood cell count (WCC) and CRP belong to the most frequently studied systemic inflammatory response markers. Only IL-6 and CRP, however, allow for differentiating the relevance and the intensity of the systemic inflammatory response caused by surgical trauma [26]. Several authors have already published results of the systemic 
inflammatory response in patients after abdominal hernia surgery in the early postoperative period (within $48 \mathrm{~h}$ after surgery) [12-14, 27-30]. Only Akhtar et al. studied the systemic inflammatory response in their patients after laparoscopic and open inguinal hernia repair up to the 5th postoperative day [31]. Our results support the hypothesis that activated systemic inflammatory response persists after open hernia surgery even on postoperative day 7-10. Levels of inflammatory markers (IL-6, CRP, $\alpha$-1-acid glycoprotein) were statistically significantly elevated on postoperative day $7-10$ as compared to preoperative levels. However, a month after the surgery, the inflammatory markers returned to the preoperative levels, which reflect the subsided systemic inflammatory response. Regarding cholecystectomy, laparoscopic surgery is associated with lower systemic inflammatory response compared to open cholecystectomy [15-17]. More significant systemic inflammatory responses in patients after open cholecystectomy are related to the magnitude of tissue trauma as a result of laparotomy. Di Vita et al. and Sista et al. measured the systemic inflammatory response after open and laparoscopic cholecystectomy till 7th and 12th postoperative day, respectively. These authors noted that IL-6 and CRP levels normalize by about the 6th or 7 th postoperative day $[15,32]$. On the contrary, our results demonstrate persisted systemic inflammatory response after laparoscopic cholecystectomy on postoperative day 7-10. Significantly elevated inflammatory markers (IL-6, CRP, $\alpha-1$-acid glycoprotein) were proven at that time. A month after the surgery, the systemic inflammatory response had subsided and the inflammatory markers dropped to baseline levels.

Postoperative hypercoagulability is an intrinsic response to surgical trauma. In general, surgical trauma induces a secondary postoperative thrombocytosis, elevated levels of fibrinogen, prothrombin fragment $\mathrm{F} 1+2$ and D-dimer [33-35]. Postoperative hypercoagulability and levels of coagulation markers can be modified by the systemic inflammatory response, type of surgery, postoperative complications and postoperative drug administration. Dedej et al. described in patients after open surgery a decrease in PLT levels $72 \mathrm{~h}$ postoperatively [10]. PLT count decrease in the early postoperative period has been explained by postoperative platelet consumption and by postoperative VTE prophylaxis administration of unfractionated heparin or LMWH [10]. Fibrinogen is a marker of activated coagulation and fibrinogen also belongs to acute phase proteins. Prothrombin fragment $\mathrm{F} 1+2$ corresponds with the formed volume of thrombin and can be regarded as a coagulation activity marker [36]. D-dimer forms during the plasmin-induced breakdown of fibrin in the fibrinolytic pathway. D-dimer is considered a common marker of coagulation activation, particularly a marker of fibrinolysis. Elevated coagulation markers have already been documented in the early postoperative period in patients after cholecystectomy and hernia surgery. Return of plasmatic fibrinogen to the preoperative level was described by Di Vita et al. on postoperative day 7 after laparoscopic and open cholecystectomy as well [15]. Patients after open cholecystectomy have higher plasmatic prothrombin fragment F1 +2 levels in the early postoperative period compared to patients after laparoscopic cholecystectomy [34, 35]. However, there are no data concerning hypercoagulability duration after surgery for benign diseases. We observed interesting results in both surgery groups of patients. Persisted hypercoagulability was proven in hernia surgery group patients on postoperative day 7-10. Statistically significantly elevated levels of all coagulation markers (PLT count, levels of fibrinogen, prothrombin fragment $\mathrm{F} 1+2$ and $\mathrm{D}$-dimer) were measured. On postoperative day $28-30$, significantly elevated levels of fibrinogen, prothrombin fragment F1 +2 and D-dimer were persistent in patients after hernia surgery. Postoperative hypercoagulability persisted in cholecystectomy group patients as well. All coagulation markers were statistically significantly elevated compared to preoperative baseline levels on postoperative day 7-10. A month after the laparoscopic cholecystectomy decrease and normalization of PLT count and D-dimer levels were observed. However, persisted markers of activated coagulation (fibrinogen, prothrombin fragment $F 1+2$ ) were proven in cholecystectomy group patients on 28th-30th postoperative day. Prolonged elevation of D-dimer levels and persisted activation of fibrinolysis in patients after open hernia repair can be explained by more extensive soft tissue trauma and the implantation of a foreign body - mesh. The hypercoagulability status was proven in our patients not only a week after but also, surprisingly, a month after hernia surgery and laparoscopic cholecystectomy.

\section{Conclusion}

Despite the long persisting hypercoagulability in patients after laparoscopic cholecystectomy and hernia surgery, the prevalence of clinically apparent VTE was low in our study population $-0.46 \%$. Our data support short-term (in hospital) postoperative VTE prophylaxis in moderate and high risk patients undergoing hernia repair or cholecystectomy.

\section{Abbreviations}

ACCP: American College of Chest Physicians; BMI: body mass index; BP: blood pressure; CRP: C reactive protein; Fbg: fibrinogen; FVL: Factor $\mathrm{V}$ Leiden mutation; F1 + 2: prothrombin fragment F1 + 2; HS: hernia surgery; IL-1: interleukin 1; IL-6: interleukin 6; IQR: interquartile range; LC: laparoscopic cholecystectomy; LMWH: low molecular weight heparin; Oroso: a-1-acid glycoprotein; PLT: platelets; SD: standard deviation; TNFa: tumor necrosis factor $a$; Trf: transferrin; VTE: venous thromboembolism. 


\section{Competing interests}

The authors declare that they have no competing interests.

\section{Authors' contributions}

$J U, T K$ and VF were the main authors of the manuscript. They were involved in the conception, design and coordination of the study as well as in data analysis, interpretation of results and the drafting of the manuscript. IM performed all laboratory tests and analysed data. MK was in charge of statistical analysis. JK jr, FB, RB and ZK monitored patients and control subjects and analysed data. JK consulted on the study and manuscript. All authors read and approved the final manuscript.

\section{Acknowledgements}

This work was supported by grants of the Ministry of Health, Czech Republic (RVO-VFN64165 and NT 13251-4).

\section{Author details}

${ }^{1} 1$ st Department of Surgery - Department of Abdominal, Thoracic Surgery and Traumatology; First Faculty of Medicine, Charles University in Prague and General University Hospital in Prague, Prague, Czech Republic. ${ }^{2}$ Thrombotic Center, Institute of Medical Biochemistry and Laboratory Diagnostics, General University Hospital, Charles University, Prague, Czech Republic. ${ }^{3}$ Institute of Biophysics and Informatics, First Faculty of Medicine, Charles University in Prague, Prague, Czech Republic. ${ }^{4}$ Department of Methodology, Faculty of Physical Education and Sport, Charles University in Prague, Prague, Czech Republic. ${ }^{5}$ Thrombotic Centre of Institute of Medical Biochemistry and Laboratory Diagnostics, General University Hospital, Karlovo namesti 32, 121 11 Prague, Prague 2, Czech Republic

Received: 16 October 2015 Accepted: 17 March 2016 Published online: 06 April 2016

\section{References}

1. Enoch S, Woon E, Blair SD. Thromboprophylaxis can be omitted in selected patients undergoing varicose vein surgery and hernia repair. Br J Surg. 2003:90:818-20.

2. Hidalgo M, Figueroa JM. Prophylaxis of venous thromboembolism in abdominal wall surgery. Hernia. 2000;4:242-7.

3. Stein PD, Matta F, Sabra MJ. Pulmonary embolism and deep venous thrombosis following laparoscopic cholecystectomy. Clin Appl Thromb Hemost. 2014;20:233-7.

4. Nguyen NT, Hinojosa MW, Fayad C, Varela E, Konyalian V, Stamos MJ, et al. Laparoscopic surgery is associated with a lower incidence of venous thromboembolism compared with open surgery. Ann Surg. 2007;246:1021-7

5. Gould MK, Garcia DA, Wren SM, Karanicolas PJ, Arcelus JI, Heit JA, et al. American College of Chest Physicians. Prevention of VTE in nonorthopedic surgical patients: Antithrombotic Therapy and Prevention of Thrombosis, 9th ed: American College of Chest Physicians Evidence-Based Clinical Practice Guidelines. Chest. 2012;141 Suppl 2:e227S-77S.

6. Samama CM, Albaladejo P, Benhamou D, Bertin-Maghit M, Bruder N, Doublet JD, et al. Committee for Good Practice Standards of the French Society for Anaesthesiology and Intensive Care (SFAR). Venous thromboembolism prevention in surgery and obstetrics: clinical practice guidelines. Eur J Anaesthesiol. 2006;23:95-116.

7. Tincani E, Piccoli M, Turrini F, Crowther MA, Melotti G, Bondi M. Video laparoscopic surgery: is out-of-hospital thromboprophylaxis necessary? J Thromb Haemost. 2005:3:216-20.

8. Lozano FS, Sanchez-Fernandez J, Santos JA, Garcia-Alovio J, Mateosa R, Gonzalez-Porras JR, et al. Venous thromboembolism risk stratification and thromboprophylaxis with low molecular weight heparin in patients undergoing major ambulatory surgery: an observational prospective study. Ambul Surg. 2010;6:5-12

9. Tsiminikakis N, Chouillard E, Tsigris C, Diamantis T, Bongiorni C, Ekonomou $\mathrm{C}$, et al. Fibrinolytic and coagulation pathways after laparoscopic and open surgery: a prospective randomized trial. Surg Endosc. 2009:23:2762-9.

10. Dedej T, Lamaj E, Marku N, Ostreni V, Bilali S. Alterations in homeostasis after open surgery. A prospective randomized study. G Chir. 2013;34:202-9.
11. Milic DJ, Pejcic VD, Zivic SS, Jovanovic SZ, Stanojkovic ZA, Jankovic RJ, et al. Coagulation status and the presence of postoperative deep vein thrombosis in patients undergoing laparoscopic cholecystectomy. Surg Endosc. 2007:21:1588-92.

12. Gürleyik E, Gürleyik G, Cetinkaya F, Unalmiser S. The inflammatory response to open tension-free inguinal hernioplasty versus conventional repairs. Am J Surg. 1998;175:179-82

13. Vatansev C, Belviranli M, Aksoy F, Tuncer S, Sahin M, Karahan O. The effects of different hernia repair methods on postoperative pain medication and CRP levels. Surg Laparosc Endosc Percutan Tech. 2002;12:243-6.

14. Bender O, Balcı FL, Yüney E, Sağlam F, Ozdenkaya Y, Sarı YS. Systemic inflammatory response after Kugel versus laparoscopic groin hernia repair: a prospective randomized trial. Surg Endosc. 2009;23:2657-61.

15. Di Vita G, Sciumè C, Milano S, Patti R, Lauria GL, Di Bella G, et al. Inflammatory response in open and laparoscopic cholecystectomy. Ann Ital Chir. 2001;72:669-73. discussion 673-4.

16. Karayiannakis AJ, Makri GG, Mantzioka A, Karousos D, Karatzas G. Systemic stress response after laparoscopic or open cholecystectomy: a randomized trial. Br J Surg. 1997;84:467-71.

17. Jakeways MS, Mitchell V, Hashim IA, Chadwick SJ, Shenkin A, Green CJ, et al. Metabolic and inflammatory responses after open or laparoscopic cholecystectomy. Br J Surg. 1994;81:127-31.

18. Dindo D, Demartines N, Clavien PA. Classification of surgical complications: a new proposal with evaluation in a cohort of 6336 patients and results of a survey. Ann Surg. 2004;240:205-13.

19. Wells PS. Advances in the diagnosis of venous thromboembolism. J Thromb Thrombolysis. 2006;21:31-40.

20. Kvasnička T, Hájková J, Bobčíková P, Cverhová V, Malíková I, Ulrych J, et al. The frequencies of six important thrombophilic mutations in a population of the Czech Republic. Physiol Res. 2014;63:245-53.

21. Just E, Botet X, Martínez S, Escolà D, Moreno I, Duque E. Reduction of the complication rate in Liechtenstein hernia repair. Int J Surg. 2010:8:462-5.

22. Keus F, de Jong JA, Gooszen HG, van Laarhoven CJ. Laparoscopic versus open cholecystectomy for patients with symptomatic cholecystolithiasis. Cochrane Database Syst Rev. 2006;18:CD006231.

23. Gabay C, Kushner I. Acute-phase proteins and other systemic responses to inflammation. N Engl J Med. 1999;340:448-54.

24. Buyukkocak U, Caglayan O, Daphan C, Aydinuraz K, Saygun O, Agalar F. Similar effects of general and spinal anaesthesia on perioperative stress response in patients undergoing haemorrhoidectomy. Mediators Inflamm. 2006;2006:97257.

25. Kahveci K, Ornek D, Doger C, Aydin GB, Aksoy M, Emre C, et al. The effect of anesthesia type on stress hormone response: comparison of general versus epidural anesthesia. Niger J Clin Pract. 2014;17:523-7.

26. Watt $D G$, Horgan PG, McMillan DC. Routine clinical markers of the magnitude of the systemic inflammatory response after elective operation: a systematic review. Surgery. 2015;157:362-80.

27. Suter $M$, Martinet $O$, Spertini F. Reduced acute phase response after laparoscopic total extraperitoneal bilateral hernia repair compared to open repair with the Stoppa procedure. Surg Endosc. 2002;16:1214-9.

28. Rahr HB, Bendix J, Ahlburg P, Gjedsted J, Funch-Jensen P, Tønnesen E. Coagulation, inflammatory, and stress responses in a randomized comparison of open and laparoscopic repair of recurrent inguinal hernia. Surg Endosc. 2006;20:468-72.

29. Jess P, Schultz K, Bendtzen K, Nielsen OH. Systemic inflammatory responses during laparoscopic and open inguinal hernia repair: a randomised prospective study. Eur J Surg. 2000;166:540-4.

30. Uzunköy A, Coskun A, Akinci OF, Kocyigit A. Systemic stress responses after laparoscopic or open hernia repair. Eur J Surg. 2000;166:467-71.

31. Akhtar K, Kamalky-asl ID, Lamb WR, Laing I, Walton L, Pearson RC, et al. Metabolic and inflammatory responses after laparoscopic and open inguinal hernia repair. Ann R Coll Surg Engl. 1998:80:125-30.

32. Sista F, Schietroma M, Carlei F, Cecilia EM, Piccione F, De Santis G, et al. The neutrophils response after laparoscopic and open cholecystectomy. Ann Ital Chir. 2013;84:153-8.

33. Folman CC, Ooms M, Kuenen BB, de Jong SM, Vet RJ, de Haas M, et al. The role of thrombopoietin in post-operative thrombocytosis. Br J Haematol. 2001:114:126-33.

34. Schietroma M, Carlei F, Mownah A, Franchi L, Mazzotta C, Sozio A, et al. Changes in the blood coagulation, fibrinolysis, and cytokine profile during laparoscopic and open cholecystectomy. Surg Endosc. 2004;18:1090-6. 
35. Prisco D, De Gaudio AR, Carla R, Gori AM, Fedi S, Cella AP, et al. Videolaparoscopic cholecystectomy induces a hemostasis activation of lower grade than does open surgery. Surg Endosc. 2000;14:170-4.

36. Boisclair MD, Ireland $\mathrm{H}$, Lane DA. Assessment of hypercoagulable states by measurement of activation fragments and peptides. Blood Rev. 1990;4:25-40.

Submit your next manuscript to BioMed Central and we will help you at every step:

- We accept pre-submission inquiries

- Our selector tool helps you to find the most relevant journal

- We provide round the clock customer support

- Convenient online submission

- Thorough peer review

- Inclusion in PubMed and all major indexing services

- Maximum visibility for your research

Submit your manuscript at www.biomedcentral.com/submit 